\title{
Amphetamine attenuation of tonic immobility in chickens
}

\author{
JAMES L. BOREN and GORDON G. GALLUP, JR. \\ State University of New York at Albany, Albany, New York 12222
}

\begin{abstract}
Contrary to the contention that the duration of tonic immobility may reflect monotonic changes in arousal, different doses of d-amphetamine were shown to differentially antagonize the reaction in chickens. Not only were response durations abbreviated, but amphetamine was also found to diminish overall susceptibility to immobility. The possibility of an amphetamine-induced increase in general activity as an alternative account of immobility attenuation was ruled out in the second experiment. In a third experiment, it was shown that the effect of amphetamine on response duration could be abolished by pretreatment with parachlorophenylalanine.
\end{abstract}

Tonic immobility, a dramatic state of motor inhibition triggered by physical restraint, has been the subject of many diverse interpretations (Ratner, 1967). Although manipulations designed to increase fear serve to prolong the reaction, and those thought to reduce fear diminish the response (e.g., Maser, Gallup, \& Barnhill, 1973), an alternative account of such changes is that they may merely reflect altered states of general arousal. In fact, Leftwich and May (1974) have argued that none of the studies purporting to show fear involvement in tonic immobility rule out arousal as a confounding influence.

Using food deprivation as a means of manipulating arousal independent of fear, Gallup and Williamson (1972), however, failed to find effects on tonic immobility. Also contrary to the arousal hypothesis, Thompson, Piroch, and Hatton (Note 1) reported that d-amphetamine, a compound widely acknowledged to increase arousal, served to antagonize tonic immobility in chickens; i.e., birds treated with amphetamine exhibited significantly shorter, rather than longer, immobility reactions. Their account of this reduction was that amphetamine may increase the animal's sensitivity to stimuli which terminate or disrupt the immobility episode (e.g., Hatton \& Thompson, 1975).

The present study was designed to replicate the Thompson et al. findings, and to examine their interpretation of the amphetamine attenuation of immobility.

\section{EXPERIMENT 1}

Although Thompson, Piroch, and Hatton (Note 1) only recorded response duration following amphet-

The authors wish to thank G. Gagliardi, S. Garrison, and L. Wallnau for help in data collection, and E. Riley for comments on an early draft of this paper. Requests for reprints should be sent to G. G. Gallup, Jr., Department of Psychology, State University of New York at Albany, Albany, New York 12222. amine injections, tonic immobility can be measured along several dimensions. The duration of the immobilized state can be used as a measure of response intensity or magnitude, while the number of standardized attempts needed to elicit immobility can be used to index overall susceptibility to the reaction (Gallup, 1974). If, as Thompson et al. suggest, the amphetamine attenuation of tonic immobility is a consequence of increased sensitivity to events which are known to terminate the response (e.g., noise), then amphetamine's action should be confined to the duration measure. Both duration and susceptibility measures were taken in the first experiment following different doses of d-amphetamine.

\section{Method}

Subjects. The subjects consisted of 30 straight-run Production Red chickens (Gallus gallus) obtained from a local hatchery at 1 day of age. The birds were group-reared in a commercial brooder, and given continuous access to chick feed and water. Fourteen hours of artificial light per day was provided throughout rearing.

Apparatus and Procedure. At 17 days posthatch, chicks were randomly selected from the brooder and divided into three groups of 10 subjects each. For control purposes, one group was given an intraperitoneal injection of $.5 \mathrm{cc}$ distilled water. Birds in the remaining two groups received IP injections of either .34 or $1.34 \mathrm{mg}$ of d-amphetamine sulfate dissolved in $.5 \mathrm{cc}$ distilled water. Based on mean body weights, which were determined after testing, doses were then calculated as group averages. This procedure was employed to minimize the amount of handling subjects received, since handling is known to attenuate tonic immobility (Nash \& Gallup, 1976), and resulted in average doses of approximately 2.5 and $10 \mathrm{mg} / \mathrm{kg}$ for the respective groups. All injections were given by an investigator who did not take part in testing.

Immediately after injection, each bird was placed in a cardboard box and transported to a separate testing room. Twenty minutes later, the bird was removed from the box, placed on a table and abruptly inverted on its right side, where gentle restraint was maintained with both hands for $15 \mathrm{sec}$. The experimenter then withdrew his hands and activated a stopwatch. Any subject failing to remain immobile was given up to five successive 15 -sec inductions in an attempt to elicit immobility. The duration of immobility was measured from the time of release until the bird showed a righting response and returned to its feet. Testing and data recording was performed by experimenters who were kept unaware of the kind of drug used and the purpose of the study. 


\section{Results}

Amphetamine not only diminished the duration of immobility, but also greatly increased the number of inductions needed for response elicitation. These effects are depicted in Figure 1. Due to heterogeneity of variance, a log transformation was applied to all duration scores prior to statistical analysis. A between-groups analysis of variance indicated significant duration differences among groups $(F=4.32$, df $=2 / 27, p<.025)$. Using Dunnett's method for comparing treatment means with a control mean (Edwards, 1968), significant differences in duration were found between both doses of amphetamine and water $(\mathrm{p}<.05)$. Analysis of the induction data also showed a statistically reliable effect of amphetamine $(F=9.32, \mathrm{df}=2 / 27, \mathrm{p}<.001)$, and Dunnett's test indicated that birds receiving either dose of amphetamine required significantly more inductions than controls $(\mathrm{p}<.05)$.

\section{EXPERIMENT 2}

Although Thompson et al. (Note 1) have argued that amphetamine may increase sensitivity to stimuli which disrupt tonic immobility, an alternative interpretation might relate to response competition. If amphetamine served to make animals generally more active, a tendency toward increased activity could compete with the inhibition of movement characteristic of tonic immobility, resulting in both lower susceptibility and abbreviated response duration. To assess this alternative, birds were tested for general activity following injections of $d$-amphetamine.

\section{Method}

The subjects were 16 Production Red chickens obtained and maintained similarly to those in the first experiment.

At 3 weeks of age, the birds were randomly divided into two groups. Chickens in one group were given intraperitoneal injections of $3.5 \mathrm{mg} / \mathrm{kg}$ of d-amphetamine sulfate dissolved in $.5 \mathrm{cc}$ distilled water, while birds in the remaining group received equivalent injections of distilled water alone. Twenty minutes after injection, birds in both groups were tested for general activity for $5 \mathrm{~min}$ in a stabilimeter platform (Lafayette 86010).

\section{Results}

Amphetamine failed to affect an increase in general activity. In fact, the differences were in just the opposite direction, with amphetamine-treated birds showing a mean activity count of only 13.63 , as compared to 35.25 for controls. However, an analysis of variance failed to provide evidence for a statistically significant difference between groups in activity $(\mathrm{F}=2.39$, $\mathrm{df}=1 / 14)$.

\section{EXPERIMENT 3}

In addition to activating central catecholaminergic systems, amphetamine may also affect central serotonergic pathways. Geyer, Dawsey, and Mandell

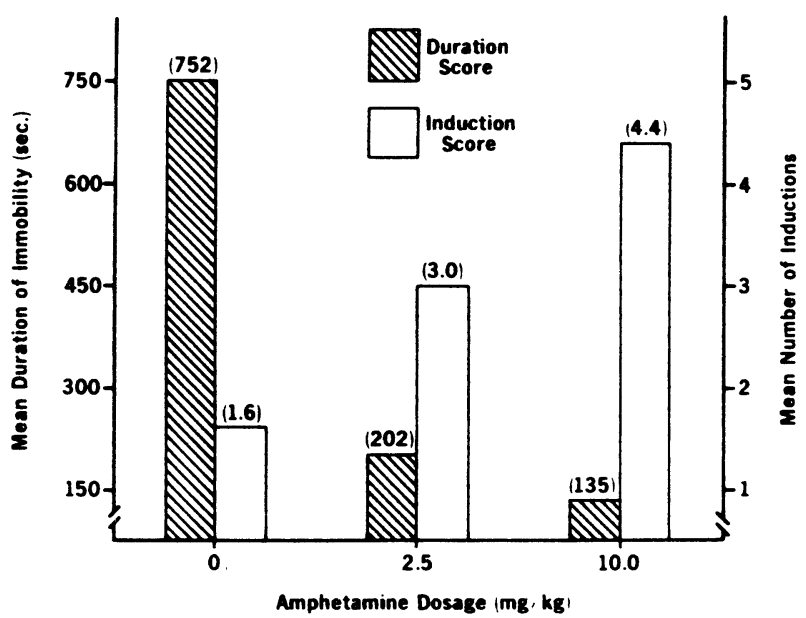

Figure 1. Effect of different doses of d-amphetamine on response duration and number of inductions needed to elicit tonic immobility in chickens.

(1975) have shown that d-amphetamine functions to inhibit tryptophan hydroxylase activity in some regions of the brain. Amphetamine is also known to increase the electrical activity of serotonergically rich raphe nuclei (Foote, Sheard, \& Aghajanian, 1969). Using 5-day-old chickens, Schrold and Squires (1971) have shown that postural changes induced by amphetamine can be eliminated if birds are pretreated with parachlorophenylalanine (PCPA), a compound thought to deplete overall brain serotonin. As an extension of the Schrold and Squires findings, the present study sought to assess the effect of serotonin blockade on amphetamine-induced changes in tonic immobility.

\section{Method}

Subjects. The subjects were 92 straight-run Production Red chickens. All birds were obtained and maintained similarly to those used in the previous experiments.

Apparatus and Procedure. At approximately 3 weeks of age, the birds were randomly assigned to two groups. One group received an IP injection of $.5 \mathrm{cc}$ distilled water, while chicks in the second group received an IP injection of $51.9 \mathrm{mg}$ of DL-p-chlorophenylalanine methyl ester $\mathrm{HC} 1$ dissolved in $.5 \mathrm{cc}$ distilled water. The method for calculating doses was the same as in the previous experiments, and yielded an average PCPA dose of $309 \mathrm{mg} / \mathrm{kg}$. After injection, each bird was fitted with a plastic legband for later identification.

Seventy-two hours after the first injection, the birds in both groups were subdivided into two additional groups of 23 each and given an IP injection of either $.57 \mathrm{mg}$ of d-amphetamine in $.5 \mathrm{cc}$ of distilled water or water alone. The average dose of amphetamine was calculated to be $3.18 \mathrm{mg} / \mathrm{kg}$. Immediately after the second injection, the birds were placed in a cardboard box and transported to a testing room. The injection-test interval, testing, and data-recording procedures were the same as in Experiment 1.

\section{Results}

One bird in the PCPA-water group died prior to testing, thereby reducing the number of subjects to 91. Table 1 summarizes the effects of the various drug treatments on response duration and susceptibility. 
Table 1

Effect of PCPA and Amphetamine on the Duration and Susceptibility to Tonic Immobility

\begin{tabular}{|c|c|c|c|c|}
\hline & $\begin{array}{l}\text { Water- } \\
\text { Water }\end{array}$ & $\begin{array}{l}\text { Water- } \\
\text { Ampl }\end{array}$ & $\begin{array}{l}\text { PCPA- } \\
\text { nine }\end{array}$ & $\begin{array}{l}\text { PCPA- } \\
\text { Water }\end{array}$ \\
\hline & \multicolumn{4}{|c|}{ Duration (seconds) } \\
\hline \multirow[t]{2}{*}{$\begin{array}{l}\bar{X} \\
\text { SD }\end{array}$} & $\begin{array}{l}320.29 \\
348.54\end{array}$ & $\begin{array}{l}86.22 \\
91.82\end{array}$ & $\begin{array}{l}534.08 \\
930.45\end{array}$ & $\begin{array}{l}171.55 \\
167.08\end{array}$ \\
\hline & \multicolumn{4}{|c|}{ Number of Inductions } \\
\hline$\overline{\mathrm{X}}$ & 1.57 & 2.21 & 2.21 & 1.14 \\
\hline SD & 1.31 & 1.51 & 1.68 & .47 \\
\hline
\end{tabular}

The decrease in immobility duration and increase in number of inductions in the water-amphetamine group replicated the findings of the first experiment. In addition, the increase in response duration to approximately control levels in the PCPA-amphetamine group parallels the findings of Schroid and Squires (1971) by showing that PCPA can block the behavioral effects of amphetamine in young chicks.

A between-groups analysis of variance of the duration data yielded evidence of significant drug effects $(F=3.55$, df $=3 / 87, p<.025)$. Duncan's multiple range test showed that the difference between PCPA-amphetamine and water-amphetamine was statistically significant $(p<.05)$, but that there was no difference between the PCPA-amphetamine group and water control, or between the PCPA-water group and water control.

Although PCPA abolished the amphetamine effect on duration of tonic immobility, it failed to block the decreased susceptibility produced by amphetamine. Table 1 shows that both amphetamine groups required more inductions than either of their respective controls. These differences were tested by analysis of variance and proved to be significant $(F=3.57, \mathrm{df}=3 / 87, \mathrm{p}<.025)$. Analysis of the differences between group means was accomplished by orthogonal comparisons. Subjects in both groups receiving amphetamine on the test day required significantly more inductions than subjects in the two groups that received water $(F=9.39, \mathrm{df}=1 / 87$, $\mathrm{p}<.005$ ), while no differences were found between the two amphetamine groups or between the two water groups.

\section{DISCUSSION}

The amphetamine effects on tonic immobility bear on the contention of Leftwich and May (1974) that fear and arousal are inextricably confounded in studies of tonic immobility. Rather than showing longer reactions, as would be predicted from an arousal hypothesis, amphetamine treated birds showed extremely brief immobility responses. By contrast, manipulations thought to increase fear, such as shock and conditioned aversive stimuli (Gallup, 1974), result in exaggerated immobility times.
The present findings replicate and extend the results reported by Thompson, Piroch, and Hatton (Note 1); however, the antagonizing effect of amphetamine was not confined to the duration measure. Amphetamine-treated birds not only showed abbreviated reactions, but were also much more difficult to immobilize (see Figure 1). The fact that birds were less susceptible to immobility raises some interesting questions about the notion that amphetamine achieves its effect by making the animal more sensitive to stimuli which disrupt tonic immobility. If anything, there are reasons to suspect that an increase in sensitivity might make subjects more susceptible to the reaction. For example, events known to terminate immobility, such as loud noise (Hatton \& Thompson, 1975), have actually been shown to increase, rather than decrease, susceptibility when presented prior to induction (see Gallup, 1974). Heightened sensitivity would also apply to the aversive properties of the induction procedure (Nash \& Gallup, 1975), and therefore maximize the conditions favoring response onset. But, as shown in both experiments, birds treated with amphetamine required significantly more inductions for response elicitation.

In the second experiment, a dose of amphetamine found to be an effective immobility antagonist in both the first and third experiments failed to produce an increase in activity on a stabilimeter platform. Thus, the presence of competing responses, associated with a possible amphetamine-induced increase in general activity, would not seem to provide a viable account of the effects of amphetamine on susceptibility or duration of immobility.

Still another possible interpretation may relate to the neurochemical effects of amphetamine. In an earlier study of the behavioral effects of several sympathomimetic amines in chickens, Key and Marley (1962) concluded that amphetamine and similar substances "produced their effect neither by the central release of noradrenaline nor by a central action on adrenaline or noradrenaline receptors" ( $p$. 104). Subsequent attempts to clarify central nervous system mechanisms involved in mediating the behavioral effects of amphetamine in birds have implicated serotonin and serotonergic neurons (Schrold, 1972; Schrold \& Squires, 1971). Congruent with these findings, chickens in the present study given PCPA prior to amphetamine evidenced immobility durations which were comparable to control subjects given only water injections. In terms of a neurochemical account, however, the present data must be viewed as only suggestive. Clearly, amphetamine is a compound which has multiple and exceedingly complex effects.

Inasmuch as the raphe nuclei are thought to be a major source of brain serotonin, however, it is interesting to note that a parallel seems to exist 
between the effect of drug manipulations on single-unit firing of mammalian raphe neurons and the duration of tonic immobility in chickens. Drugs which decrease raphe firing (Aghajanian \& Haigler, 1973; Foote, Sheard, \& Aghajanian, 1969) have also been shown to increase immobility durations (Maser, Gallup, \& Hicks, 1975). The experiments reported here strengthen this parallel. In spite of its presumed effect on serotonin synthesis, Aghajanian and his co-workers have found no effect of PCPA on raphe firing. Not only was tonic immobility unaffected by PCPA in the present study, but the lack of a PCPA effect on immobility has been noted in several previous reports (Hicks, Maser, Gallup, \& Edson, 1975; Maser et al., 1975). Further, since drugs which suppress raphe electrical activity seem to potentiate tonic immobility, one might predict that a compound known to increase raphe firing ought to decrease immobility duration. Amphetamine is just such a drug (Foote et al., 1969), and, as shown in Experiments 1 and 3, amphetamine did antagonize tonic immobility. Perhaps changes in the electrical activity of raphe nuclei, and not serotonin per se, are functionally related to changes in the duration of immobility.

It is important to acknowledge, however, that unlike duration, the amphetamine-induced decrease in susceptibility was not modified by serotonin depletion. Birds given PCPA followed $72 \mathrm{~h}$ later by amphetamine showed much more prolonged reactions, but remained less susceptible to tonic immobility (see Table 1). This apparent dissociation of effects on duration and susceptibility lends support to the contention that these may be independent parameters of tonic immobility (e.g., Gallup, Ledbetter, \& Maser, 1976).

\section{REFERENCE NOTE}

1. Thompson, R. W., Piroch, J., \& Hatton, D. The effect of sympatholytic and sympathomimetic drugs on the duration of tonic immobility (animal hypnosis) in chickens. Paper presented at the meeting of the Midwestern Psychological Association, Chicago, May 1973.

\section{REFERENCES}

Aghajanian, G. K., \& Haigler, H. J. Direct and ind irect actions of LSD, serotonin and related compounds on serotonin-containing neurons. In J. Barchas \& E. Usdin (Eds.), Serotonin and behavior. New York: Academic Press, 1973.
EDWARDS, A. L. Experimental design in psychological research. New York: Holt, Rinehart, \& Winston, 1968.

Foote, W. E., Sheard, M. H., \& Aghajanian, G. K. Comparison of effects of LSD and amphetamine on midbrain raphe units. Nature, 1969, 222, 567-569.

Gallup, G. G., JR. Animal hypnosis: Factual status of a fictional concept. Psychological Bulletin, 1974, 81, 836-853.

Gallup, G. G., JR., LedbetTer, D. H., \& MASER, J. D. Strain differences in tonic immobility: Evidence for an emotionality component. Journal of Comparative and Physiological Psychol$o g y, 1976$, in press.

Gallup, G. G., JR., \& Williamson, G. T. Effect of food deprivation and a visual cliff on tonic immobility. Psychonomic Science, 1972, 29, 301-302.

GeYer, M., Dawsey, W., \& MANDEll, A. Differential effects of caffeine, d-amphetamine, and methylphenidate on individual raphe cell flourescence: A microspectrofluorimetric demonstration. Brain Research, 1975, 85, 135-139.

Hatton, D. C., \& Thompson, R. W. Termination of tonic immobility in chickens by auditory stimulation. Bulletin of the Psychonomic Society, 1975, 5, 61-62.

Hicks, L. E., Maser, J. D., Gallup, G. G., JR., \& Edson, P. H. Possible serotonergic mediation of tonic immobility: Effects of morphine and serotonin blockade. Psychopharmacologia, 1975, 42, 51-56.

KEY, B., \& MARLEY, E. The effect of sympathomimetic amines on behavior and electrocortical activity of the chicken. Electroencephalography and Clinical Neurophysiology, 1962, 14, 90-105.

LEFTWICH, D., \& MAY, J. G. Effects of conditioned aversive stimuli presented during tonic immobility in guinea pigs. Journal of Comparative and Physiological Psychology, 1974, 87, 513-516.

Maser, J. D., Gallup, G. G., JR., \& Barnhill, R. Conditioned inhibition and tonic immobility: Stimulus control of an innate fear response in the chicken. Journal of Comparative and Physiological Psychology, 1973, 83, 128-133.

Maser, J. D., Gallup, G. G., JR., \& Hicks, L. E. Tonic immobility: Possible involvement of monoamines. Journal of Comparative and Physiological Psychology, 1975, 89, 319-328.

NASH, R. F., \& GALlUP, G. G., JR. Aversiveness of the induction of tonic immobility in chickens (Gallus gallus). Journal of Comparative and Physiological Psychology, 1975, 88, 935-939.

Nash, R. F., \& Gallup, G. G., JR. Habituation and tonic immobility in domestic chickens. Journal of Comparative and Physiological Psychology, 1976, 90, 870-876.

RATner, S. C. Comparative aspects of hypnosis. In J. Gordon (Ed.), Handbook of clinical and experimental hypnosis. New York: Macmillan, 1967.

SCHROLD, J. Behavioral effects of d-amphetamine alone and in combination with antidepressants, antihistamines or other psychotropic drugs in young chicks. Psychopharmacologia, 1972, 23, 115-124.

SChrold, J., \& Souires, R. Behavioral effects of d-amphetamine in young chicks treated with p-C1-phenylalanine. Psychopharmacologia, 1971, 20, 85-90.

(Received for publication April 29, 1976; revision accepted June 30,1976 .) 